\title{
Revisiting the issue of class structure in Labor and Monopoly Capital
}

\author{
Revisitando a questão da estrutura de classes no Labor and Monopoly Capital \\ Bruno Tinel ${ }^{1}$
}

\begin{abstract}
The application by the capitalists of the Taylorian principles of management on a large scale leads to a separation of conception from execution. According to Braverman, the main effect of this propagation is to polarize class structure. Nevertheless, he also identified several counter-tendencies. The process involves both deskilling and reskilling movements and it is not fully convincing to say that there for sure is a class polarization. The counter-tendencies can therefore not be taken as minor nor as necessarily dominated by the class polarization tendency. Therefore, the global outcome is likely to be more indeterminate and unstable than suggested by Braverman.
\end{abstract}

Keywords: Class Structure. Class polarization. Division of labour. Labour process theory. Deskilling.

\section{Resumo}

A aplicação feita pelos capitalistas dos princípios taylorianos de gestão em larga escala leva a uma separação entre concepção e execução. De acordo com Braverman, o principal efeito dessa propagação é polarizar a estrutura de classes. No entanto, ele também identificou várias contra-tendências. O processo envolve tanto a desqualificação e os movimentos de requalificação, e não é totalmente convincente para dizer com certeza que é uma polarização de classes. Portanto, as contra-tendências não podem ser consideradas como menores, nem como necessariamente dominadas pela tendência na polarização de classes. Assim, é provável que o resultado global seja mais indeterminado e instável do que o sugerido por Braverman.

Palavras-chave: Estrutura de classes. Polarização de classes. Divisão do trabalho. Teoria do processo de trabalho. Desqualificação.

Paper submitted on February 27 $7^{\text {th }}, 2014$ and accepted for publication on August $21^{\text {st }}, 2014$.

DOI: http://dx.doi.org/10.1590/1679-395117007

A previous version of this article has been presented at the Sixth Historical Materialism Annual Conference, 27-29 November 2009, SOAS and Birkbeck, London.

1 Associate Professor, Paris 1 Panthéon-Sorbonne University, Economics Department. Address: Centre d'Economie de la Sorbonne, Maison des Sciences Economiques, 106 boulevard de l'Hôpital, 75013, Paris, France. E-mail: btinel@univ-paris1.fr 


\section{Introduction}

The masterpiece of Braverman encloses a rich conception of class structures. Because the application of the capitalist principles described by Marx in the chapter 14 of Capital vol. 1 to any labour process induces a separation between conception and execution, Braverman contends that the development of the capitalist production tends to lead to class polarization. ${ }^{2}$ In fact his positive analysis leads to a more subtle and indeterminate outcome. To him, such a separation process determines the transformations of both the organisation of production and the class structure. In the Marxian framework, class structure is grounded on property relations as well as on specializations arising from the manufacturing division of labour.

This paper is a contribution to the ongoing and unending debate on class structure in modern capitalism (COSTHEK ABÍLIO, 2011; DAS, 2012; HANAPPI and HANAPPI-EGGER, 2012, SAVAGE, DEVINE, CUNNINGHAM et al., 2013). It shows that it is possible, inside the Marxian framework based on the usual worker/capitalist opposition developed in Capital vol. I, to derive a process of class segmentation instead of necessarily calling forth polarization. By proceeding to a careful and detailed reading of Labor and Monopoly Capital this article shows that, beyond the personal intentions and preferences of the author, the positive and genuine analysis of class structure led by Braverman does not necessarily lead to a polarization. ${ }^{3}$ In other words, although he clearly identifies both tendencies and counter-tendencies to class polarization, their outcome cannot clearly be decided on a theoretical basis. Nevertheless, to conclude that the class structure can be either polarized or more segmented is in itself a theoretical result. The main outcome of this contribution is to show that the core of the Marxian approach, that can be found in Labor and Monopoly Capital, is able to generate inside its own system of analysis more segmented class structures than the usual worker/capitalist opposition. Such a binary matrix is grounded on property relations and still remains in the basic set of hypotheses of the analytical system, the present article suggests that this fundamental class opposition is likely to lead in the course of the capitalist development to more segmented class structures made of hybrid segments which are not easily reducible to one or the other of the two fundamental classes.

Marx himself has developed both conceptions of class structure: the binary one dominates in the Manifesto whereas he adopts a more segmented view of the French society in the $18^{\text {th }}$ Brumaire. When he takes into account the diverse forms of production that exist in a class society like the capitalist mode of production at a given historical time, Marx then notices that other forms of production remain under the domination of the capitalist one. Indeed, some elements of the previous modes of production progressively transforme, like the feudal lords who became capitalists, or slowly disappear while other productions continue to exist under the same form like the independent self-employed producers. For this reason, "in any specific class society, there are always more classes than those connected to the existing mode of production." (MILIOS, 2000, p. 295). Nevertheless, Marx shows in vol. I that a particular mode of production being based on a particular mode of exploitation logically and necessarily involves only two basic classes struggling one against each other. In the capitalist mode of production, the separation of the worker from the means of production forms the core of the class relations between workers and capitalists. It is also true that Marx noticed, especially in Capital vol. 3, that the development of the capitalist mode of production induces new functions that emerge as autonomous social forces which obviously contribute to class segmentation. However, the present paper does not pretend to give a new synthesis of the debates on the nature of class structures in Marx's various and numerous writings. Here the focus is much narrower and more modest but also clear-cut. Braverman is probably one of those who developed the deepest understanding of the chapters 13,14 and 15 of vol. I. He takes over, reinterprets, develops and generalizes Marx's analysis of the division of labour. He proposes new reflexions on the impact of new technologies and of the systematic diffusion of management. He shows that the Taylorian logic of the capitalist division of labour, already identified by Marx only in the most advanced

2 Braverman notably shows how the Taylorian principles systematize the separation between conception and execution as they appear merely as a normative statement formalizing the class interest of the capitalists in the sphere of production.

3 A case for a renewed and radical reading of Braverman can be found in Spencer (2000), the present paper has to be considered as taking up this challenge. 
industries of his time, invaded a lot of new sectors and activities especially services during the $20^{\text {th }}$ Century. As shown by the title of his book, this process is interpreted as a degradation of work. In short, Braverman's global argument is that the diffusion of the capitalist division of labour produces a global and massive deskilling process which induces class polarization. Still, a careful reading of his book shows that this polarization tendency is not the only outcome that can emerge from his own analysis. The present paper shows that Braverman can be reinterpreted differently: even when the surviving pre-capitalist forms of production are set aside the very logic of the capitalist production development which rests upon two basic classes can lead to class segmentation. This interpretation does not resort to new theoretical elements pertaining for instance to the sophistication of circulation such as in vol. 3, the basic argument rests on Braverman's analysis of the division of labour in the shop-floor.

The reading of Taylor by Braverman is presented in the first section where the very own logic of the capitalist division of labour is understood as a process of separation of conception from execution. As this movement induces a better control over the labour process for the capitalist, the Taylorian principles are to be considered as a formalisation of the basis of management. The second section examines how, according to Braverman, the development of this management has an impact on class structure through the modifications of skills, of jobs and of organisations. Braverman considers that the main effect of the diffusion of the Taylorian practices is to polarize the distribution of people in two fundamental classes, however it can be shown that the author perceives also clearly counter-tendencies leading to the emergence of "middle layers" which he tries unsuccessfully to reduce to the two previous classes. The third section summarizes and concludes.

\section{Taylor by Braverman}

Following Marx step by step in his analysis of labour, labour power and the division of labour in the first three chapters of his book, Braverman emphasises that in a wage relation, the worker sells "the power to labor over an agreed period of time." (BRAVERMAN, p. 37, emphasis by Braverman) to the capitalist. As s/he cannot purchase labour directly as such, the capitalist has to set the worker to work. Hence, the worker may be constrained to "accept" the disintegration of the unity of work: thus conception is likely to be separated from execution. The labourer specialises in execution and her/his employer specialises in conception; s/he has the authority to steer labour power, although this authority may never totally be accepted by the subordinate. This steering issue is designed by Braverman as the management problem: "the progressive alienation of the process of production from the worker." (BRAVERMAN, p. 39-40, emphasis by Braverman). Just as command is double sided for Marx, management is double sided for Braverman: it entails both coordination and control (TINEL, 2012). To improve her/his management of labour power, the capitalist has to change and reshape the labour process continuously. Changing technology can be a means for such transformations, but it is not necessarily required. The main objective of the management is to maximise the extraction of surplus value and accumulation. As this process develops, the management becomes more and more self-conscious and thoroughly gauging. Taylor and others were major actors of this process.

\section{The genesis of management}

Braverman emphasises that the subdivision of production work into its constituent elements is not sufficient to create the detail worker. Any labour process organised by workers themselves is likely to be divided as well into separate tasks repeatedly fulfilled one after the other by the same person during a certain amount of time. Just like Babbage, and later on Marglin, Braverman points out the crucial (and overlooked) role played by specialization in a few simple tasks in the capitalist labour process: "Not only are the operations separated 
from each other, but they are assigned to different workers" (p. 54) ${ }^{4}$. The detail worker is created by the assignment of each worker to a limited number of tasks. This creation of simple labour cheapens each part of the labour, makes it more dependent and increases the control of capital. The Babbage principle plays a major role in the capitalist system especially because it can be applied to any form of labour at any level of the hierarchy (TINEL, 2013).

Ure and Babbage, as well as the classical economists are considered by Braverman as the first management experts because they were the first intellectuals who paid theoretical attention to the organisation of labour in the capitalist relations of production. But Braverman acknowledges Taylor as a genuine originator of management both theoretically and practically. He played a major and decisive role by bringing the "comprehensive formulation of management theory" (p. 59) in the late $19^{\text {th }}$ century. ${ }^{5}$ On the basis of the analysis of Taylor's "scientific management", Braverman reformulates its global definition as follows: "Scientific management, so-called, is an attempt to apply the methods of science to the increasingly complex problems of the control of labour in rapidly growing capitalist enterprises. It lacks the characteristics of a true science because its assumptions reflect nothing more than the outlook of the capitalist with regard to the conditions of production" (p. 59). The scientific management's point of view is hence neither "neutral" nor "objective" as it endorses the "point of view of the management of a refractory work force in a setting of antagonistic social relations. It does not attempt to discover and confront the cause of this condition, but accepts it as an inexorable given, a "natural" condition. It investigates not labour in general, but the adaptation of labour to the needs of capital. It enters the workplace not as the representative of science, but as the representative of management masquerading in the trappings of science" (id.). Management theory as a whole is built on Taylor's principles and Braverman emphasizes that theses principles are applied in a way or another by the experts of "human relations" and "industrial psychology". But, eventually, Taylor should be seen less as an "inventor" than as the culmination of a pre-existing movement.

For Braverman, the originality of "scientific management" compared with previous approaches is the focus on control: "Taylor raised the concept of control to an entirely new plan when he asserted as an absolute necessity for adequate management the dictation to the worker of the precise manner in which work is to be performed. (...) His "system" was simply a means for management to achieve control of the actual mode of performance of every labour activity, from the simplest to the most complicated." (p. 62, emphasis by Braverman)

\section{The basic content of Taylor's management}

The purpose of Taylor is both to ensure management control and to cheapen the contribution of the worker. He makes two important but implicit hypotheses. First, each human is supposed to loaf and soldier "naturally" and systematically and works only under constraint, this main behavioural feature of human beings is not different from the standard approach. ${ }^{6}$ For this reason, managers cannot rely on the initiative of workers. Second, as long as s/he is not working to its physiological maximum, the worker is not considered by Taylor as accomplishing "a fair day's work". Contrary to what is supposed by the standard economic theory, the pay of labour is socially determined and relatively independent of productivity. On this basis,

\footnotetext{
4 "The worker may break the process down, but he never voluntarily concerts himself into a lifelong detail worker. This is the contribution of the capitalist (...) in destroying the crafts as a process under the control of the worker, he reconstitutes it as a process under his own control." (BRAVERMAN, p. 54-5).

5 "Taylor understood the Babbage principle better than anyone of his time." (BRAVERMAN, p. 81). Babbage is viewed by Braverman as a forerunner of Taylor because he applied the same concept to the division of mental labour.

${ }^{6}$ The issue of behavioral preconceptions about work is discussed extensively by Spencer (2009).
} 
formal subordination cannot be sufficient to obtain the "desired" level of work. ${ }^{7}$ Real subordination has to be deepened in order to withdraw the control of the labour process from the hands of the labour power as much as possible.

For Taylor, the use of money to induce the workers to work harder and more rapidly is convenient only in the first stages of a new mode of work. Once a higher pace of effort has been reached, it is better to rely on control over the decisions that the worker has to make throughout work. Eventually, the principles of this socalled "scientific management" of Taylor come down to three precepts.

1. Braverman designs the first principle as "the dissociation of the labour process from the skills of the workers." (p. 78). In the earliest times of the industrial revolution, the knowledge of the labour process was traditionally controlled by the craftsmen. For Taylor this knowledge has to be collected in the hands of the management. This gives the possibility for the management to predetermine the quality of the labour and to control it through the work design which renders also possible a better control of the quantity of labour extracted. ${ }^{8}$

2. Second principle: "the separation of conception from execution". Human labour is a combination of conception and execution, in contrast with animal activity which consists only in execution as conception is genetically predetermined. If for Taylor, workers have to be specialised in execution, Braverman considers it as a "de humanisation of the labour process [because] workers are reduced almost to the level of labour in its animal form." (BRAVERMAN, p. 78) 9

3. Third principle: "control each step of the labour process and its mode of execution" by the monopoly over knowledge ( $2^{\text {nd }}$ principle). A key element of labour control by management is the "systematic pre-planning and pre-calculation of all elements of the labour process, which no longer exists as a process in the imagination of the worker but only as a process in the imagination of a special management staff." (BRAVERMAN, p. 82).

Modern management is both a theoretical construction and a systematic practice based on those three principles initially elaborated for production workers. These basic principles crudely formalize nothing else than the capitalist way of dividing labour in the production process. Braverman shows that they are applied also to any kind of work: clerical work, services, retail trade, unproductive labour, management activities etc. Braverman considers merely that Taylor's principles played a great role "to render conscious and systematic, the formerly unconscious tendency of capitalist production". (BRAVERMAN, p. 83). This capitalist way of managing the production process and dividing labour is also one of the main forces shaping class structure as a whole. By looking merely at the separation between conception and execution, one can think that the class

7 Braverman was probably not aware of the practical distinction made by Marx between formal and real subsumtion of labour under capital in the unpublished $6^{\text {th }}$ chapter of Das Kapital, but he had such an accurate knowledge of volume I, which is implicitly stamped by theses notions, that we can use the terms here without twisting Braverman's thought. The following quotation shows that the formal/real distinction suits Braverman's words perfectly well eventhough he does not use it: "Workers who are controlled only by general orders and discipline are not adequately controlled, because they retain their grip on the actual process of labour. So long as they control the labour process itself, they will thwart efforts to realise to the full the potential inherent in their labour power. To change this situation, control over the labour process must pass into the hands of management, not only in a formal sense but by the control and dictation of each step of the process, including its mode of performance. In pursuit of this end, no pains are too great, no efforts excessive, because the results will repay all efforts and expenses lavished on this demanding and costly endeavour." (BRAVERMAN, p. 69).

8

"The labour process is to be rendered independent of craft, tradition, and the worker's knowledge. Henceforth it is to depend not at all upon the abilities of workers, but entirely upon the practices of management." (BRAVERMAN, p. 78).

9 Braverman prefers the conception/execution couple to the more common mental/manual dichotomy "because mental labour, labour done primarily in the brain, is also subjected to the same principle of separation of conception from execution: mental labour is first separated from manual labour and (...) is then itself subdivided rigorously according to the same rule." (BRAVERMAN, p. 78). 
structure generated by the dissemination of capitalist management is binary, but it can eventually be found to be more segmented.

\section{Tendencies and Counter-tendencies to Class Polarization}

Braverman sticks to the idea stated initially in the Manifesto that the capitalist development necessarily implies a polarization of the class structure between capitalists and workers. Hence, the number of workers is considered as growing progressively to such an extent that it will eventually outnumber and overthrow their oppressors in order to create a new economic system of their own. ${ }^{10} \mathrm{~A}$ very fruitful intuition of Braverman is that if class structure is determined in the final analysis by property relations it is firstly (re)produced everyday in the social relations of production by the organisation of production itself; this idea is also very operative in Capital, Volume 1. Braverman has forcefully and intentionally stood by the polarization thesis through his analysis of deskilling. Nevertheless a careful reading of his book shows that his genuine positive and scientific contribution on the issue of class structure is much more unexpected and indeterminate than what is suggested by his own political and strategical preferences. A close reading can show that although Braverman identified both tendencies and counter-tendencies to class polarization their combination is likely to give a more segmented class structure than the usual binary capitalist / worker opposition.

In the remainder of this section, the basic statement for polarization and its main counter-tendencies are presented, then other contradictory arguments are examined. The general and explicit treatment of the "middle layers" by Braverman is presented in the third subsection. The fourth is devoted to a discussion about the role of science and technology in the determination of class structure and the last subsection discusses the issue of productive and unproductive labour in relation to class structure.

\section{The basic statement for polarization and its main counter-tendencies}

The polarization thesis is stated as follows by Braverman at the end of his third chapter in the conclusion of his general discussion on the division of labour: "the relatively few persons for whom special knowledge and training are reserved are freed so far as possible from the obligation of simple labour. In this way, a structure is given to all labour processes that at its extremes polarises those whose time is infinitely valuable and those whose time is worth almost nothing." (BRAVERMAN, p. 57-8). Braverman is convinced that the class structure tends to be binary through a polarization of skills and occupations. This way of organising work is hence the driving force of polarization and he contends that it is stronger than any other force acting in another way. It shapes not only work but also populations as a whole: classes are merely grounded in the organisation of work. But meanwhile he also highlights all along his argument other factors acting as counter tendencies to this polarization.

At the beginning of the chapter 5 devoted to "the primary effects of scientific management", Braverman reckons that the separation of mental work from manual work induces a reduction in the number of workers engaged directly in production because "it divests them of time-consuming mental functions and assigns these functions elsewhere." (BRAVERMAN, p. 86). ${ }^{11}$ The argument leads to believe that the lower class of production-execution workers does not grow as fast as the "middle class" formed of mental workers inside the organisation. Somewhat in contradiction with the idea of polarization? Actually, this kind of hesitation is an inherent part of Braverman's argument. On the one hand, it is argued that the process of separation

\footnotetext{
${ }^{10}$ Despite a growing evidence against a binary class structure in the most advanced capitalist countries, this argument was not much questionable among Marxist thinkers during the whole 20th century.

${ }^{11}$ At this level of the analysis, it is not clear if the "workers engaged directly in production" refer only to the couple conception/execution or to the couple unproductive/productive labour. Further, this ambiguity remains unsolved also because Braverman does not consider any conception work as necessarily unproductive, which is legitimate.
} 
between conception and execution is going on and on in each sector, in each occupation, in each segment of the organisation etc. And eventually the conception work itself is even subjected to routinisation and fragmentation. ${ }^{12}$ This aspect of separation produces deskilling and hence class polarization. On the other hand, as the process of separation goes on, the manual-production-execution work is made less and less necessary inside the organisation which goes against class polarization if one considers only the employment structure. Of course, if unemployment is to be taken into consideration then the analysis becomes a bit more complicated as it has to answer the question of the "rate of recycling" of the former superfluous deskilled labor force into reskilled labor force. In the chapter 17 of his book Braverman overlooks this "recycling" issue and seems to advocate absolute pauperization which of course supports greatly the polarization thesis.

Still in the 5th chapter, Braverman relevantly notices that the conception/execution separation induces a spatial separation of workers on different sites. The production workers are thus controlled and supervised by a remote management centre which reproduces all its activities "on the paper". The creation of this remote management is clearly obtained by the creation of new occupations which is acknowledged by Braverman: "This paper replica of production, the shadow form which corresponds to the physical, calls into existence a variety of new occupations, the hallmark of which is that they are found not in the flow of things but in the flow of paper." (BRAVERMAN, p. 87). This argument shows that Braverman obviously perceives that new skilled occupations specialised in conception are more and more created as the conception/execution separation process goes on. This phenomenon proceeds against class polarization. But on the same page, the polarization thesis is "saved" by the argument that "conception is concentrated, insofar as possible, in ever more limited groups within management or closely associated with it." (BRAVERMAN, p. 87).

The entire book is stuck between those two contradictory statements: i) the separation of conception from execution leads to deskilling and class polarization and ii) less and less workers are engaged directly in production while more and more workers are needed for conception which leads to a reskilling process and class segmentation. The ingenious trick by which Braverman tries to get out of this jam is to cleverly and systematically demonstrate that even conception and supervision work can be subjected to a separation between conception and execution: as already noticed conception can indeed be formalised, routinised and subdivided into different simplified tasks. In fact, the division between conception and execution is used by capitalists everywhere. ${ }^{13}$ Finally his argument is that even the so-called "new occupations" are also deskilled or low-skilled jobs. Hence, for him this third "middle" class is nothing but a part of the working class exploited by the class of capitalists.

\section{The persistent indeterminacy of class structure}

The difficulty is that Braverman clearly sees that the implement of this deskilling process and this incredible centralisation of conception and control requires relatively skilled and autonomous work, which can here again go against polarization: "At first glance, the organisation of labour according to simplified tasks, conceived and controlled elsewhere (...) have a clearly degrading effect upon the technical capacity of the worker. In its effects upon the working population as a whole, however, this matter is complicated by the rapid growth of specialised administrative and technical staff work, as well as by the rapid growth of production and the shifting of masses to new industries and within industrial processes to new occupations." (BRAVERMAN, p. 88) 14 $^{14}$ Braverman further develops this argument in chapter 10 which discusses the role of technology on the distribution of labour. He opposes "production workers" to "clerical work" (or non

\footnotetext{
12 Braverman shows indeed brilliantly how most of the office workers, often called in the past "white collars", who were supposed to work in conception tasks were actually also subjected to execution work, which tendency contributes seriously to blur the frontier between the lower and the middle class by attracting downwards a great part of the latter.
}

13 "No part of capitalist employment is exempt from the methods which were first applied on the shop floor." (p. 88)

14 The same idea is expressed again on page 165: "the more striking tendency is the marked change in occupational composition within these industries. (...) the separation of conceptualisation from execution -the removal of all possible work from the shop floor, the point of execution, to the office- and the further necessity of maintaining a shadow replica of the entire process of production in paper form, brings into being large technical and office staffs." 
production workers), which gathers both productive (like engineers, technicians...) and unproductive workers involved in administrative, financial or marketing tasks. The rise of the separation between conception and execution implicated the creation of a new mass occupation of skilled workers (engineers etc.) that were then deskilled, at least partially, by the application of the Taylor system and by mechanisation. It is crucial to read what Braverman notes about this decisive phenomenon: "The enormous and continuous growth in demand for engineers has created a new mass occupation. On the one hand, this has, along with other new professions such as accounting, given a place to those thrust out of the old middle class by the relative decline of the petty entrepreneurial occupations in trade and other erstwhile arenas of small business. But on the other hand, having become a masse occupation engineering has begun to exhibit, even if faintly, some of the characteristics of other mass employments: rationalisation and division of labour, simplification of duties, application of mechanisation, a downward drift in relative pay, some unemployment, and some unionisation." (BRAVERMAN, p. 167, emphasis added by BT). The counter tendency is here counteracted by the tendency to polarization but only "faintly", which means that Braverman implicitly acknowledges that this countertendency to polarization can at least be of some importance. ${ }^{15}$

The polarization tendency is all the more likely to be weak that deskilled labour is progressively replaced by machinery not only in the workshop but also in offices. This tends to reduce the relative proportion of deskilled jobs. But, in fact, Braverman believes in polarization and seeks clues that support this argument, for example: "new drafts of workers are brought into jobs that have already been degraded in comparison with the craft processes of before; but inasmuch as they come from outside the existing working class, chiefly from ruined and dispersed farming and peasant populations, they enter a process unknown to them from previous experience and they take the organisation of work as given." (BRAVERMAN, p. 89). There would have been a double movement where only "short term openings" of advancement arise for a minority of workers meanwhile ever lower skills are required at the entry for large masses of workers. The counter tendency to polarization "simply masks the secular trend toward the incessant lowering of the working class as a whole below its previous conditions of skill and labour." (BRAVERMAN, p. 89). This general movement of deskilling induces for Braverman a modification of the notion of skill towards depreciation in order to keep differentiation in recruitment.

Another counter tendency is identified by Braverman in a footnote on page 123. It relates to the increased number of supervisors required by the enforcement of the new standards, surprisingly it is not really developed in the remainder of the book. And this counter tendency is in turn potentially eliminated by the replacement of supervisors themselves by automatic systems of control (see p. 146).

\section{The treatment of the "Middle Layers" in the $18^{\text {th }}$ chapter}

The global thesis of Braverman on polarization is explicitly treated only in the four pages composing the $18^{\text {th }}$ chapter of the book where he tackles directly the specific features of the "middle layers of employment" as he calls them. For Braverman, this portion of employment is profoundly stamped by the formal definition of the working class. Being in possession of only its labour force, this class is economically dependent on the class owning the means of production and is hence compelled to work for a wage which is the only access to the means of subsistance. ${ }^{16}$

\footnotetext{
${ }^{15}$ This idea is expressed in the following terms on page 169: "Thus the very process which brought into being a mass engineering profession is being applied to that profession itself when it has grown to a large size, is occupied with duties which may be routinized, and when the advance of solid-state electronic technology makes it feasible to do so."

16

${ }^{6}$ About this middle class, Braverman considers that "unlike the earlier middle-class [petty bourgeoisie] (...) it corresponds increasingly to the formal definition of a working class. That is, like the working class it possesses no economic or occupational independence, is employed by capital and its offshoots, possesses no access to the labour process or the means of production outside that employment, and must renew its labour for capital incessantly in order to subsist. This portion of employment embraces the engineering, technical, and scientific cadre, the lower ranks of supervision and management, the considerable numbers of specialised and "professional" employees occupied in marketing, financial and organisational administration, and the like, as well as, outside of capitalist industry proper, hospitals, schools, government administration and so forth." (BRAVERMAN, p. 279). Note that Braverman
} 
The two extreme points of the wage working class polarization are described in the following terms: "The form of hired employment gives expression to two totally different realities: in one case, capital hires a "labour force" whose duty it is to work, under external direction, to increase capital; in the other, by a process of selection within the capitalist class and chiefly from its own ranks, capital chooses a management staff to represent it on the spot, and in representing it to supervise and organise the labours of the working population." (BRAVERMAN, p. 280). On the one side, workers are hired to execute orders and, on the other, some are employed to give orders to the formers on behalf of capital. For Braverman, those who are giving orders are unambiguously coming from the capitalist class. Between those two extremes, Braverman identifies that the "new" middle class takes its characteristics from both sides: "a range of intermediate categories, sharing the characteristics of worker on the one side and manager on the other in varying degrees. The gradation of position in the line of management may be seen chiefly in terms of authority, while gradations in staff positions are indicated by the levels of technical expertise. Since the authority and expertise of the middle ranks in the capitalist corporation represent an unavoidable delegation of responsibility, the position of such functionaries may best be judged by their relation to the power and wealth that commands them from above, and to the mass of labour beneath them which they in turn help to control, command and organise. Their pay level is significant because beyond a certain point it, like the pay of the commanders of the corporation, clearly represents not just the exchange of their labour power for money $-\mathrm{a}$ commodity exchange- but a share in the surplus produced in the corporation, and this is intended to attach them to the success or failure of the corporation and give them a "management stake", even if a small one" (BRAVERMAN, p. 280, emphasis by BRAVERMAN). Managers have then to be considered as belonging to the capitalist class not only because they are selected from its own ranks but also because their salary is high enough to be considered as a share of the profit. The other people forming this middle class look different from, and situated above, the working class because they have some authority and technical expertise but they actually belong to the working class and "their true place in the relations of production, their fundamental condition of subordination as so much hired labour, increasingly makes itself felt, especially in the mass occupations that are part of this stratum" (BRAVERMAN, p. 282). Here again, Braverman "saves" the polarization thesis by considering that most of this middle class feels more and more like belonging to the working class and is objectively part of it. Indeed, the author tries to conclude by arguing that those workers of the new middle class are more and more conscious of their proletarian condition, but this element is not much documented and discussed. With only five pages this chapter is among the shortests of the book. The author merely writes without any empirical or theoretical justification that "In such occupations, the proletarian form begins to assert itself and to impress itself upon the consciousness of the employee. Feeling the insecurities of their role as sellers of labor power and the frustrations of a controlled and mechanically organized workplace, they begin, despited their remaining privileges, to know those symptoms of dissociation which are popularly called "alienation" and which the working class has lived with for so long that they have become part of its second nature" (BRAVERMAN, $p$. 282). This statement looks more like an invocation than a demonstration and forty years later one must admit that this prophecy is far from being realized in the most advanced capitalist economies where it was supposed to occur.

As an intermediate summary we can say that 1 / Braverman in the end of his book perfectly sees that the dynamics of the division of labour leads to the emergence of a "new" middle class which features hybridity (wage and command); 2/ Braverman considers this class merely as an illusion because in actual fact its top layers belong to the capitalist class whereas the remainder is genuinely part of the working class. This second statement is however difficult to acknowledge on the basis of a positive analysis because Braverman fails to demonstrate the impossibility of a real class hybridity. Another way of treating this issue inside the Marxian framework supposes to give up the polarization hypothesis and to merely consider hybridity as an emergent property of the interaction between classes and the development of the capitalist production. This is the method already adopted by Duménil and Lévy in their long term analysis of the transformations of the capitalist system (DUMÉNIL and LÉVY, 2004; 2011). Indeed, both authors apply the hybridity argument to

includes in this group without much justification those working in public administration and non capitalist sectors and he includes nearly all the population in the employees of capital but this last hypothesis really lacks an argumentation. 
the analysis of the segmentation of dominating classes, in particular their treatment of the managers as a separate class has proved to be very fruitful. The remainder of the present paper shows that Braverman's analysis of the dynamics of the division of labour is an excellent basis for the study of class segmentation.

\section{Science, technology and class structure}

James R. Bright found that on the individual level of the shopfloor, the relation between skills and the level of mechanisation is non linear. ${ }^{17}$ On page 154 , Braverman represents this relation in a chart. It increases up to a certain threshold and then decreases to apparently converge asymptotically towards zero. At the macro level, this immediately implies that any global increase in the amount of machinery does not necessarily induce polarization. Nevertheless, if considering only this relation, polarization should arise only if the mechanization durably grows faster than employment in the shopfloor which is likely to occur frequently as it has been noticed already that production workers are made less and less necessary as the process of separation goes on. Deskilling seems thus to be an inevitable outcome of the shopfloor mechanization, which fuels the polarization thesis, but as less and less workers are used for direct production this polarization effect of mechanization is attenuated on the long term.

Besides and despite Bright's curve, the main counter tendency against polarization results perhaps from the role of science and technology. From the end of the $19^{\text {th }}$ century onwards, occurred what Braverman names the scientific-technical revolution which he interprets as the transformation of science itself into capital. ${ }^{18}$ The development of machinery has gone hand in hand with the development of new sectors specialized in the conception and production of machines which has called for new occupations to conceive and produce those machines. These new sectors themselves have been responsible in their turn for the developments of other new specialized sectors and the creation of new highly skilled occupations etc. The class polarization is eventually counteracted not only by the reduction of demand of unskilled labour but also by the increase of demand of skilled labour "not yet subjected" in new fields of industry that result of the extension of the use of new technologies. ${ }^{19}$ As a consequence, there seems to exist a strong relation of complementarity between both deskilling and reskilling processes through machinery and technology which makes it hard to determine theoretically if polarization occurs or not. This opens on to empirical considerations and no prejudice for or against polarization can be reasonably deduced from Braverman's more abstract and general reflections on science and technology.

In addition, some sectors like services are less likely than others to be mechanised. They benefit from the relative surplus population released by other industries. The excess of labour power resulting from mechanisation and productivity improvements in industry insures low wages for services where labour tends to flood in on the long run. ${ }^{20}$ It is true that workers in the service sector then endure more competition one

\footnotetext{
${ }^{17}$ In chapter 9, Braverman refers extensively to Automation and Management, published by James R. Bright in 1958.
}

18

"The new scientific-technical revolution which replenished the stock of technological possibilities has a conscious and purposive character largely absent from the old. In place of spontaneous innovation indirectly evoked by social progresses of production came the planned progress of technology and product design. This was accomplished by means of the transformation of science itself into a commodity bought and sold like other implements and labour of production. From an "external economy", scientific knowledge has become a balance-sheet item." (BRAVERMAN, p. 114).

19 "The principle is itself restrained in its application by the nature if the various specific and determinate processes of production. Moreover, its very application brings into being new crafts and skills and technical specialities which are at first province of labour rather than management. Thus in industry all forms of labour coexist: the craft, the hand or machine detail worker, the automatic machine or flow process. But far more important than this relative restraint on the operation of the principle is the resulting continual shifting of employment. The very success of management in increasing productivity in some industries leads to the displacement of labour into other fields, where it accumulates in large quantities because the processes employed have not yet been subjected -and in some case cannot be subjected to the same degree- to the mechanising tendency of modern industry. The result is therefore not the elimination of labour, but its displacement to other occupations and industries." (p. 119 emphasis by BRAVERMAN).

20 "Those industries and labour processes subjected to mechanisation release masses of labour for exploitation in other, generally less mechanised, areas of capital accumulation. With the repeated manifestations of this cycle, labour tends to pile up in the industries and occupations which are less susceptible to engineered improvements in labour productivity. Wage rates in these "new" industries 
against another, which keeps wages on low levels, but it is hard to deduce from this an element clearly favouring polarization as the conception/execution separation cannot be applied as deeply as it is in industrial sectors. By definition, the service sector remains on average in an intermediate situation in terms of the development of the capitalist division of labour inside organisations. But this doesn't inform much about the deskilling issue because skills are actually not only intrinsic capacities, they are relative to the state of competition between workers to get jobs. In short, workers and even jobs can be high skilled, if workers are easily replaceable then they will only have a weak control on their labour and also a feeble bargaining power. This discussion shows that the level and the structure of unemployment has to be taken into account to determine whether or not this particular worker is able or not to retain autonomy in the labour process and bargaining power. Here again the outcome of the analysis is that contradictory forces are playing one against each other and it is difficult to conclude clearly which one is the strongest. Again, the issue looks mainly empirical rather than theoretical.

\section{Productive and unproductive labour}

In addition to the new occupations resulting from the extension of the division of labour and the technicalscientific revolution, the general historical trend of capitalism towards monopoly is understood by Braverman as creating a demand for more unproductive labour specialised in the realisation and the appropriation of surplus value by capital. ${ }^{21}$ As this constitutes a counter tendency to polarization, Braverman considers just after those statements that "We have already described the manner in which (...) the balance is shifted toward indirect labour so that labour in the mass, as it is applied directly in production, may be lessened in numbers and controlled in its activities. This shift creates a small proportion of technical jobs, most of them closely linked to management, and a larger proportion of lower-grade routinised technical or unskilled clerical jobs." (BRAVERMAN, p. 178). Here again Braverman advocates ex post the deskilling tendency thesis to immunise the reader against the counter tendency line of argument though it is not more self-evident than earlier, considering the clues given by Braverman, that the polarization effect should be stronger than its counter-tendency.

In chapters 12 and 15, Braverman recognises once more the massive rise of new occupations in big corporations described by authors like Chandler. Here again, he adds without really demonstrating his assertion that the new occupations remain somehow marginal: "But though proportionately small in the total population, this stratum has become very large in comparison with the pre-monopoly situation." (BRAVERMAN, p. 180, emphasis added by BT). And even if this stratum was proportionally greater in the total population, it wouldn't be a counter tendency to polarization because most of those new unproductive functions resulting from the delegation of management tasks ${ }^{22}$ are themselves deskilled and less

and occupations are held down by the continuous availability of the relative surplus population created by the steadily increasing productivity of labour in the machine occupations. This in turn encourages the investment of capital in forms of the labour process which require masses of low-wage hand labour. As a result, we see in capitalist industry a secular trend to accumulate labour in those portions of industry and trade which are least affected by the scientific-technical revolution: service work." (BRAVERMAN, p. 265).

21.

"In tracing this mass of labour, we will be led not only to "newly formed branches of production" in Marx's sense, but also, as were Baran and Sweezy, into branches of nonproduction, entire industries and large sectors of existing industries whose only function is the struggle over the allocation of the social surplus among the various sectors of the capitalist class and its dependents." (BRAVERMAN, p. 177). See also this quotation from the end of the book, "With the routinisation of the processes of producing value and surplus value, the attention of the capitalist is increasingly centered upon this realisation problem, the solution of which becomes even more important than the creation of value. At the same time, as the surpluses created in production become ever more immense, the use of capital simply for purpose of credit, speculation, etc., increases enormously. In this latter case, what is involved is the appropriation of portions of the surplus commodity value which arises in production. These two functions, the realisation and the appropriation by capital of surplus value, engage, as we have seen, enormous masses of labour, and this labour, while necessary to the capitalist mode of production, is in itself unproductive, since it does not enlarge the value or surplus value available to society or to the capitalist class by one iota."

22 See also Braverman, (p. 209): "entire "industries" come into existence whose activity is concerned with nothing but the transfer of values and the accounting entailed by this." And (p. 210): "Thus the value-form of commodities separates itself out from the physical form as a vast paper empire which under capitalism becomes as real as the physical world, and which swallows ever increasing amounts of labour. This is the world in which value is kept track of, and in which surplus value is transferred, struggled over, and 
differentiated from other activities ${ }^{23}$ as a result of the application of Taylor principles ${ }^{24}$ : "The particular management function is exercised not just by a manager, nor even by a staff of managers, but by an organisation of workers under the control of managers, assistant managers, supervisors etc. Thus the relation of purchase and sale of labour power, and hence alienated labour, have become part of the management apparatus itself. Taken all together, this becomes the administrative apparatus of the corporation. Management has become administration, which is a labour process conducted for the purpose of control within the corporation, and conducted moreover as a labour process exactly analogous to the process of production [emphasised by BT], although it produces no product other than the operation and coordination of the corporation. From this point on, to examine management means also to examine this labour process, which contains the same antagonistic relations as are contained in the process of production." (BRAVERMAN, p. 185). The unproductive functions are made less and less advantaged over other occupations by rationalisation: "The unproductive functions, having evolved from special and privileged occupations closely associated with capital into divisions of corporate activity or even into capitalist "industries" separate and complete in themselves, have now produced their armies of wage-workers whose conditions are generally like those of the armies of labour organised in production (...) This distinction has lost its social force as a line of division between proletarians and middle class." (BRAVERMAN, p. 289-90). This justifies for Braverman to classify most of the unproductive employed population among the working class. The author does as if no intermediary layer remained between bosses and production workers. It is not exaggerated to state that Braverman overlooks the permanency of hierarchy of pay, status and authority ensuing from "rationalisation".

Braverman shows that the capitalist (i.e. taylorian) treatment applied to every kind of labour is always the same: the separation of manual and mental work by a rationalisation process leads to the creation of new occupations where people are specialised in conception, supervision and control; on the other hand, numerous workers are more and more specialised in execution labour. The same principles are applied also to clerical work and other occupations in their turn, then the new skilled jobs are turned into deskilled and simplified labour too. The same applies also for the growth of management function, at the "end" most of the new jobs become deskilled. But there is no end as such because new sectors and new ways of managing, controling and supervising are emerging more or less regularly. For Braverman, conception and skilled labour end up being extraordinarily concentrated in only a few hands because new reskilling occupations are progressively caught up by the taylorian logic. For him no middle class is really emerging, there is only a new form of large proletariat. Nevertheless, it has been shown that Braverman is not taking seriously enough his own findings which should have led him to conclude more carefully that the class structure is largely indetermined: it can be polarized but it is also likely to be segmented in more than two layers.

allocated. A society which is based upon the value-form surrenders more and more of its working population to the complex ramifications of the claims to ownership of value."

23 "All labour processes are adjudged equally useful -including those which produce, realise, or divert the surplus. The productive and unproductive forms of labour are mingled, in individual firms and in the economy as a whole, on an equal footing. And the organisation of labour in the unproductive aspects of corporate activity follows the lines laid down in the productive sector; the labour of both sectors becomes, increasingly, an undifferentiated mass." (BRAVERMAN, p. 288).

24 "The management functions of control and appropriation have in themselves become labour processes. They are conducted by capital in the same way that it carries on the labour processes of production: with large labour purchased on a large scale in a labour market and organised into huge "production" machines according to the same principles that govern the organisation of factory labour." (BRAVERMAN, p. 208). See also (p. 288): "the measuring of the productivity of labour has come to be applied to labour of all sorts, even labour which has no productivity." (emphasis by BRAVERMAN). 


\section{The class structure revisited}

As shown in this paper, the application by the capitalists of the Taylorian principles of management on a large scale leads to a separation of conception from execution. Such principles are progressively implemented to any single feature of the production process that involves labour and even to management itself. According to Braverman, the main effect of this propagation is to polarize class structure: those who have a special knowledge and are also relieved from the obligation of simple labour are only a small number. On the other hand, a growing part of the working population is supposed to end up locked in with a simple labour of execution. Nevertheless, besides this general tendency that he considered to be dominant Braverman also identified several counter-tendencies such as the progressive reduction in the number of workers engaged directly in production, the continuous creation of new skilled occupations for remote management, control, conception, science and technology, etc. The complementarity between new occupations and deskilled jobs looks very strong because the deskilling process requires "new" skilled occupations and even if the "new" occupations will in turn enter the deskilling process, some other "newnew" occupations will be necessary to deskill the former "new" occupations; in the meantime the first deskilled jobs will probably have been replaced by automatic systems. Hence, the process involves both deskilling and reskilling movements and it is not fully convincing to say that there for sure is a class polarization because the reskilling process can be strong and as it is coupled with a tendency to replace simple labour by automatic systems, there can exist middle layers during a long period of time. The countertendencies can therefore not be taken as minor nor as necessarily dominated by the class polarization tendency. In other words, the interactions between the tendencies to polarization and the counter-tendencies identified by Braverman are much more uncertain than he suggested. Therefore, the global outcome is likely to be more indeterminate and unstable than suggested by Braverman. If the system only creates new occupations slowly then there can be a tendency to class polarization, if for a reason or another (a change in the speed of accumulation, some innovations etc.) the system creates new occupations faster there can be a tendency to a growing middle-class instead. Finally a new question arises: what are the crucial elements that lead the new occupations to grow faster/slower than the deskilled jobs?

\section{References}

BABBAGE, C. Economy of machinery and manufacture. McLean, Virginia: IndyPublish, 1832.

BRAVERMAN, H. Labor and monopoly capital. Monthly Review Press, 1974 (25 ${ }^{\text {th }}$ Anniversary edition, 1998).

COSTHEK ABÍLIO, L. Is the 'new Brazilian middle class' going to paradise? Second National Development Conference (CODE). Brasília, Brazil, November 2011.

DAS, R. J. Reconceptualizing Capitalism: Forms of Subsumption of Labor, Class Struggle, and Uneven Development. Review of radical Political Economics, v. 44, n. 2, p. 178-200, 2012.

DUMÉNIL, G.; LÉVY, D. Production and Management: Marx's Dual Theory of Labor. In: WESTRA, R.; ZUEGE, A. Value and the World Economy Today. Production, Finance and Globalization. Palgrave: London, 2004.

The crisis of neoliberalism. Harvard: Harvard University Press, 2011.

HANAPPI, H.; HANAPPI-EGGER, E. Middle Class or in the middle of a Class? In: AHE/FAPE/IIPPE conference, Paris, 5-8 July, 2012.

MARGLIN, S. What do bosses do? The origins and functions of hierarchy in capitalist production, Review of Radical Political Economics, v. 6, n. 2, p. 60-112, 1974.

MARX, K. The Eighteenth Brumaire of Louis Bonaparte, 1852. Available at: <http://www.marxists.org /archive/marx/works/1852/18th-brumaire/index.htm>. Access on: 8/29/2014. 
Capital, Vol. I, 1867. Available at: <http://www.marxists.org/archive/marx/works/download/pdf/CapitalVolume-I.pdf>. Access on: 8/29/2014.

Capital, Vol. III, 1894. Available at: <http://www.marxists.org/archive/marx/works/download/pdf/CapitalVolume-III.pdf>. Access on: 8/29/2014.

Chapter Six. Results of the direct production process (1864). In: MARX, K.; ENGELS, F. (Eds.). Economic Manuscripts of 1861-64. Marx \& Engels Collected Works, v. 34. New York: International Publishers, 1994.

; ENGELS, F. Manifesto of the Communist Party,1848. Available at: <http://www.marxists. org/archive /marx/works/download/pdf/Manifesto.pdf>. Access on: 8/29/2014.

MILIOS, J. Social Classes in Classical and Marxist Political Economy. American Journal of Economics and Sociology, v. 59, n. 2, p. 283-302, 2000.

SAVAGE, M. et al. A New Model of Social Class: Findings from the BBC's Great British Class. Sociology, v. 47, n. 2, p. 219-250, 2013.

SPENCER, D. A. Braverman and the contribution of labour process analysis to the critique of capitalist production twenty-five years on. Work, Employment and Society, v. 14, n. 2, p. 223-243, 2000.

The Political Economy of Work. London: Routledge, 2009.

TINEL, B. Labour power, labour process, division of labour, co-operation, technology. In: FINE, B.; SAAD-FILHO, A. (Eds.). The Elgar Companion to Marxist Economics. Cheltenham: Edward Elgar, 2012. 187-93 p.

Why and How Do Capitalists Divide Labour? From Marglin and Back again through Babbage and Marx.

Review of Political Economy, v. 25, n. 2, p. 254-272, 2013. 